\title{
Serum angiopoietin is associated with lung function in patients with asthma: a retrospective cohort study
}

\author{
Kuk-Young Moon ${ }^{1}$, PuReun-HaNeul Lee ${ }^{1}$, Sung-Woo Park ${ }^{1,2}$, Choon-Sik Park ${ }^{1,2}$ and An-Soo Jang ${ }^{1,2^{*}}$
}

\begin{abstract}
Background: Angiopoietin-1 (Ang-1) is an essential mediator of angiogenesis that establishes vascular integrity, and angiopoietin-2 (Ang-2) acts as its natural inhibitor. We considered that angiopoietin might be important in bronchial asthma.

Methods: In total, 35 patients with asthma and 20 healthy subjects were studied.

Results: The serum Ang-1 levels were significantly elevated in patients with asthma compared to control subjects $(293.9 \pm 13.8 \mathrm{pg} / \mathrm{mL}$ vs. $248.3 \pm 16.2 \mathrm{pg} / \mathrm{mL}$, respectively, $\mathrm{p}=0.04)$. The serum Ang-2 levels were not different between the two groups. The areas under the curve (AUC) for serum angiopoietins revealed that the serum level of Ang-1 (0.68) was more sensitive and specific than the serum Ang-2 level (0.55) for differentiating between patients with asthma and control subjects. The serum Ang-1/Ang-2 ratio was correlated with the FEV1/FVC ratio $(r=-0.312, p=0.02)$, while serum Ang-2 was correlated with body mass index.

Conclusions: Our results indicate that the serum Ang-1 levels were higher in asthma patients compared with healthy subjects. As the Ang-1/Ang-2 ratio was related to lung function, the data suggest that serum angiopoietin is associated with lung function in patients with asthma.
\end{abstract}

Keywords: Angiogenesis, Angiopoietin-1, Angiopoietin-2, Asthma

\section{Background}

Increased angiogenesis is a well-documented feature of airway remodeling in asthma [1-6]. Angiogenesis is defined as the formation of new blood vessels from preexisting endothelium. Airway remodeling [2] in asthmatic patients involves a wide array of pathophysiological features, including epithelial changes, increased smooth muscle mass, increased numbers of activated fibroblasts/ myofibroblasts, subepithelial fibrosis, angiogenesis, alterations in extracellular matrix components, and vascular changes. Multiple cytokines, chemokines, and growth factors released from inflammatory and structural cells in airway tissue create a complex signaling environment that

\footnotetext{
* Correspondence: jas877@schmc.ac.kr

${ }^{1}$ Genome Research Center for Allergy and Respiratory Diseases,

Soonchunhyang University Bucheon Hospital, 170 Jomaru-ro, Wonmi-gu,

Bucheon, Gyeonggi-do 420-767, Republic of Korea

${ }^{2}$ Department of Internal Medicine, Division of Allergy and Respiratory

Medicine, Soonchunhyang University Bucheon Hospital, 170 Jomaru-ro,

Wonmi-gu, Bucheon, Gyeonggi-Do 420-767, South Korea
}

drives these structural changes. Previous studies suggested that neovascularization and microvascular leakage are prominent in asthmatic airways [2-7]. Vascular endothelial growth factor (VEGF) is one of the most potent proangiogenic factors [8]. Angiogenesis can be initiated by endogenous angiogenic factors released from mesenchymal cells and/or inflammatory cells [9]. Under physiological conditions, angiogenesis is controlled by the equilibrium between the proendogenous and antiendogenous angiogenic factors released from the extracellular matrix [10]. In experimental models, administration of angiopoietin-2 (Ang-2) provokes microvascular leakage in the lungs and other organs [11,12], whereas Ang-1 protects against microvascular leakage induced by VEGF, Ang-2, or inflammatory agents [13-16]. Ang-2 is released from endothelial cells [17] and human monocytes [18], while various other tissue cells produce Ang- 1 . Both Ang- 1 and Ang-2 bind to Tie2 receptor, which is abundantly expressed in lung endothelium [19]. It was reported that Ang-1 and Ang-2 levels 
were increased in sputum supernatant in severe refractory asthmatics and mice [20-22]. Therefore, we examined the serum levels of angiopoietins in patients with asthma and investigated the possible associations with physiological variables.

\section{Methods \\ Subjects}

We retrospectively studied clinical data on 35 asthma patients (Table 1) who were registered in an asthma cohort of the Genome Research Center for Allergy and Respiratory Diseases in Korea. All patients were recruited from Soonchunhyang University, Bucheon Hospital. Asthma diagnoses were based on GINA guidelines [23]. All subjects had a clinical diagnosis of asthma that was supported by one or more of the following criteria: 1) variability in the maximum diurnal peak expiratory flow of greater than $20 \%$ over the course of 14 days, 2) an increase in FEV1 of greater than $15 \%$ after the inhalation of 200 $400 \mu \mathrm{g}$ of albuterol, or 3 ) a $20 \%$ reduction in FEV1 in response to a provocative concentration of inhaled methacholine (PC20 methacholine) of less than $10 \mathrm{mg} / \mathrm{mL}$. All subjects underwent standardized assessments, which included analyses of induced-sputum specimens, a complete blood cell count with a differential count, IgE measurement, chest posteroanterior radiography, allergy skin prick tests, and spirometry. All data were collected at the time of diagnosis, before the administration of asthma medication.

Asthmatic subjects matched to normal controls in terms of age, sex, and body mass index (BMI) were selected from among the asthma cohort of Bucheon Hospital for inclusion in this study. The normal control

Table 1 Clinical and physiological variables in patients with bronchial asthma and control subjects

\begin{tabular}{lll}
\hline & Normal controls & Asthmatic patients \\
Variables & $\mathbf{n = 2 0}$ & $\mathbf{n}=\mathbf{3 5}$ \\
\hline Age, yr & $51.4( \pm 8.9)$ & $46.6( \pm 13.7)$ \\
Sex $(\mathrm{M} / \mathrm{F})$ & $13 / 7$ & $15 / 20$ \\
Smoke $(\mathrm{SM} / \mathrm{ES} / \mathrm{NS})$ & $5 / 2 / 10$ & $5 / 8 / 20$ \\
Atopy $(\mathrm{Y} / \mathrm{N})$ & $6 / 14$ & $17 / 18$ \\
Asthma period, yr & 0 & $1.53( \pm 0.72)$ \\
IgE $(\mathrm{pg} / \mathrm{ml})$ & $72.08( \pm 84.0)$ & $260.11( \pm 514.0)$ \\
BMI $\left(\mathrm{kg} / \mathrm{m}^{2}\right)$ & $23.72( \pm 2.89)$ & $23.97( \pm 3.01)$ \\
FVC $(\%$, predicted $)$ & $91.40( \pm 9.1)$ & $73.00( \pm 14.6)^{*}$ \\
FEV $(\%$, predicted $)$ & $103.0( \pm 8.7)$ & $74.0( \pm 16.6)^{*}$ \\
FEV $_{1} / \mathrm{FVC} \%$ & $86.0( \pm 4.9)$ & $74.9( \pm 10.8)^{*}$ \\
PC20 methacholine & $23.87( \pm 5.05)$ & $3.11( \pm 4.63)^{*}$ \\
\hline
\end{tabular}

${ }^{*} \mathrm{p}<0.001$ compared with control subjects.

Plus-minus values are mean \pm S.D. PC20 methacholine; the concentration of methacholine required to decrease the FEV1 by $20 \%$, FEV1; forced expiratory volume in one second. FVC; forced vital capacity. BMl; body mass index. SM; smoker, ES; ex-smoker, NS; non-smoker. subjects were spouses of the patients or members of the general population who answered negatively to a screening questionnaire regarding respiratory symptoms and other allergic diseases, had a predicted FEV1 value greater than $80 \%$, a PC20 methacholine greater than $10 \mathrm{mg} / \mathrm{mL}$, and normal findings on simple chest radiographs. The exclusion criteria included respiratory infection during sputum induction, chronic obstructive pulmonary disease (COPD), vocal cord dysfunction, obstructive sleep apnea, Churg-Strauss syndrome, cardiac dysfunction, allergic bronchopulmonary aspergillosis, and poor adherence to treatment. The local research ethics committee of the Soonchunhyang University Hospital Research Board approved the study protocol. All patients and control subjects were recruited over a period of 3 months. Serum samples were collected at the time of diagnosis before the administration of asthma medication and at the time of control subject recruitment to minimize bias due to the storage time of the patient samples and the measurement of serum angiopoietins.

\section{Lung function analyses}

Spirometry [24] was performed before and after bronchodilator use. Baseline FVC and FEV1 measurements were obtained in the absence of bronchodilator use (within 8 h). Basal and post-bronchodilator FEV1 and FVC were measured. We used a Vmax Series 2130 Autobox Spirometer (Sensor Medics Corp., Yorba Linda, CA, USA) and performed a calibration check every morning at $8 \mathrm{am}$.

\section{Allergy skin tests}

Skin prick tests were performed using 24 common inhalant allergens, including dust mites (Dermatophagoides farinae and Dermatophagoides pteronyssinus), cat fur, dog fur, cockroaches, grass, tree, pollens, ragweed, and Aspergillus species (Bencard Co.; Brentford, UK) [25]. Atopy was defined as either having a wheal reaction from the allergen equal to or greater than the histamine wheal $(1 \mathrm{mg} / \mathrm{mL})$ or at least $3 \mathrm{~mm}$ in diameter. Total IgE was measured using the UniCAP system (Pharmacia Diagnostics, Uppsala, Sweden).

\section{BMI}

The BMI of the subjects [26-28] was calculated as weight $(\mathrm{kg}) /$ height $\left(\mathrm{m}^{2}\right)$.

\section{Mediator assays}

Ang-1 and Ang-2 levels were assessed in serum supernatant samples using ELISAs according to the manufacturers' instructions. The minimum detectable dose of Ang-1 and Ang-2 ranged from 1.36-10.3 pg/mL and 1.20$21.3 \mathrm{pg} / \mathrm{mL}$ (R\&D Systems, Minneapolis, MN, USA), respectively. Blood was drawn to evaluate serum albumin levels using laser nephelometry. All values were expressed 
in pg/mL. For Ang-1 and Ang-2, the intra- and inter-assay variability values were $3.5 \%$ and $6.3 \%$, respectively.

\section{Statistical analyses}

The data were double entered into a statistical software package (SPSS, version 14.0; SPSS Inc., Chicago, IL, USA). The data are expressed as means \pm standard deviation (SD). Group differences between the asthmatic patients and control subjects were compared using two-sample $t$-tests, Mann-Whitney tests, or Pearson's chi-square tests for normally distributed, skewed, or categorical data, respectively. A value of $p<0.05$ was taken to indicate statistical significance.

\section{Results}

The serum Ang-1 levels were significantly elevated in the patients with asthma compared to those in the control subjects $(293.9 \pm 13.8 \mathrm{pg} / \mathrm{mL}$ vs. $248.3 \pm 16.2 \mathrm{pg} / \mathrm{mL}$, respectively, $\mathrm{p}=0.04$; Figure 1 ). The serum Ang-2 levels did not differ between the two groups $(7.35 \pm 0.57 \mathrm{pg} / \mathrm{mL}$ vs. $7.31 \pm 0.80 \mathrm{pg} / \mathrm{mL}$, respectively; Figure 1). The AUC for serum angiopoietins indicated that the serum Ang-1 levels (0.68) were more sensitive and specific than the serum Ang-2 levels (0.55) for differentiating patients with asthma from control subjects (Figure 2).

There were no differences between the two groups in terms of atopy, IgE level, smoking status, or sex. The FEV1, FVC, FEV1/FVC, and PC20 methacholine were lower in patients with asthma compared to control subjects. The serum Ang-1/Ang-2 ratio was correlated with the FEV1/ FVC ratio (all subjects: $\mathrm{r}=-0.298, \mathrm{p}=0.027$; asthmatic patients: $r=-0.312, p=0.02$; Figure 3). Serum Ang-2 was correlated with BMI (all subjects: $\mathrm{r}=-0.427, \mathrm{p}=0.001$; asthmatic patients: $r=-0.353, p=0.038$; Figure 4). Serum Ang-1 and Ang-2 levels were not correlated with clinical parameters such as atopy, IgE level, and sputum eosinophilia.

\section{Discussion}

Our results indicate that the serum Ang-1 levels were higher in asthmatics than in healthy subjects, and that the serum
Ang-1/Ang-2 ratio was correlated with lung function, suggesting that angiopoietins are useful markers for the diagnosis of asthma.

Angiogenesis and vascular remodeling are key events in fundamental physiological processes, including growth and development, wound healing, organ regeneration, inflammation, and reproduction [29-31]. Increased size and numbers of bronchial blood vessels are also present, suggesting that angiogenesis is an essential component of tissue growth and remodeling in asthma [32]. Blood vessels are crucial for embryonic organ growth and the repair of wounded tissues in adults because they carry oxygen to the newly formed tissue. Angiogenesis is an important event in the development of allergic inflammation, as well as in the pathophysiology of tissue remodeling in asthma [6].

Angiogenesis is tightly regulated by a number of factors $[28,33]$. Ang- 1 is predominantly expressed in perivascular cells during development but is constitutively expressed in adult tissues [34]. The role of Ang-2, the second Tie2 binding partner, appears to be more complex. In contrast to Ang-1, Ang-2 is only minimally expressed (or not expressed at all) in most normal adult tissues. However, it is strongly and rapidly upregulated in endothelial cells at sites of intensive vessel remodeling, including the female reproductive system and tumors [35].

The bronchial submucosa of patients with asthma has increased numbers of vessels in large as well as medium and small airways, which occupy a larger percentage of area than in normal subjects $[5,36,37]$. Airway vascular remodeling and inflammation may be responsible for increased bronchial blood flow [38] and exhaled breath temperature gradients in patients with asthma [39].

Ang-1 inhibits vascular permeability without affecting vascular morphology. Endothelial cells need to loosen the interendothelial cell contacts to emigrate from their resident sites [40]. Ang-2, an inhibitor of Tie2 signaling, may be involved in detaching smooth muscle cells and loosening the matrix [40]. Once the intracellular contacts have been loosened, VEGF initiates endothelial network

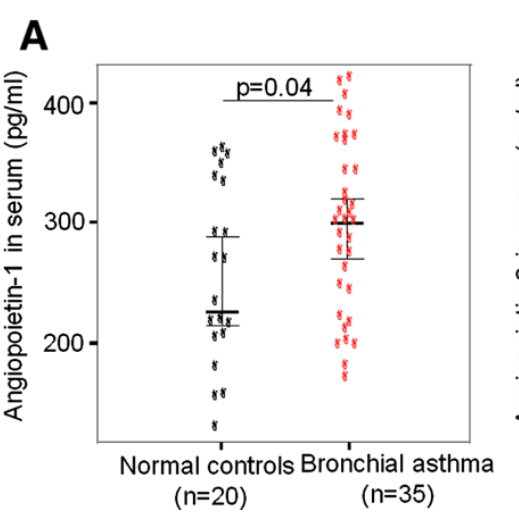

B

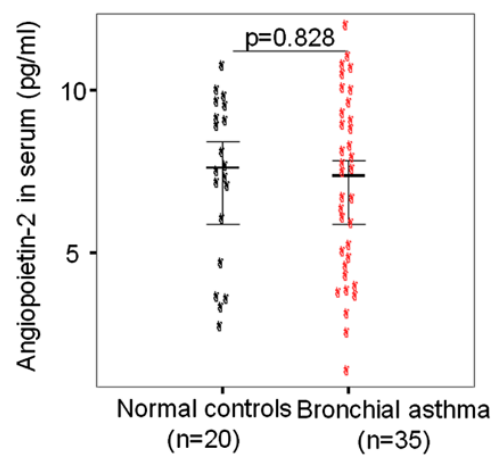

Figure 1 Serum angiopoietin 1 (A) and angiopoietin 2 (B) levels in patients with asthma and healthy controls. 


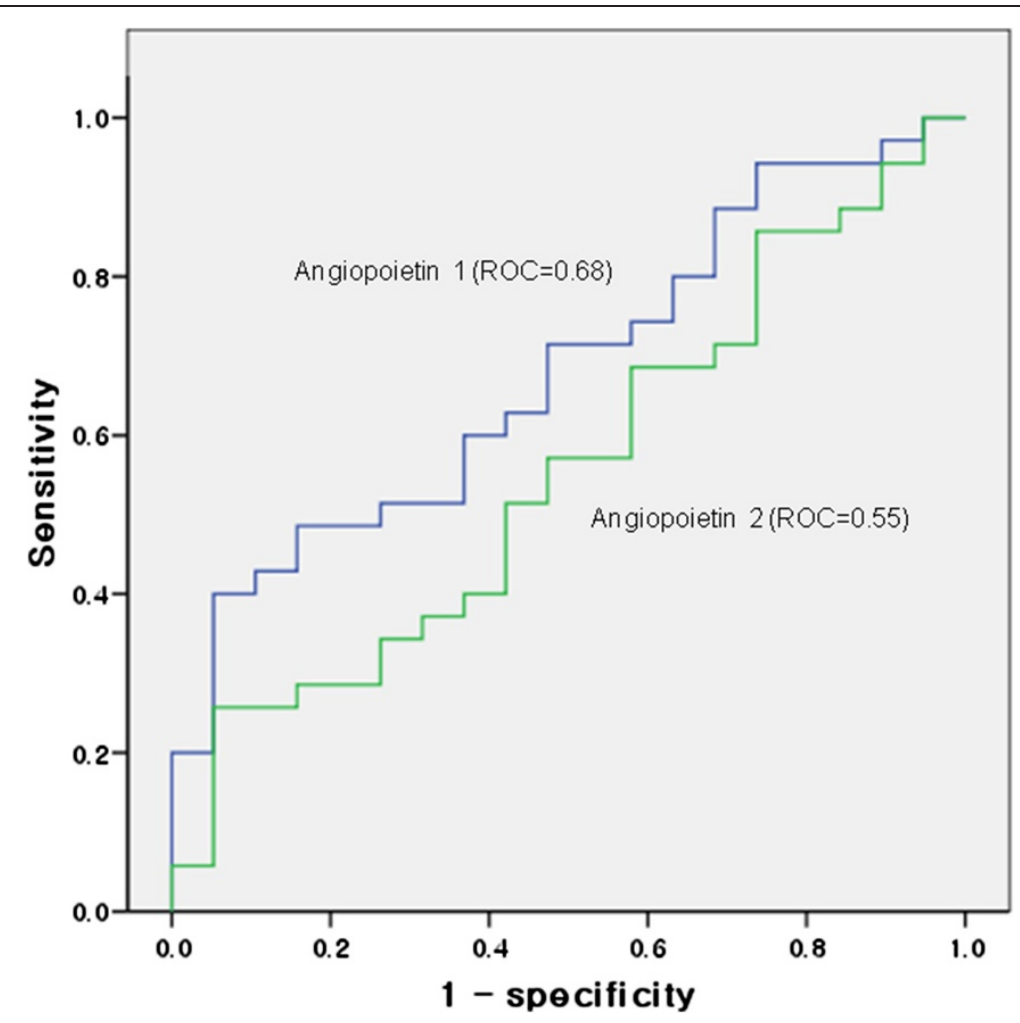

Figure 2 Serum angiopoietin 1 and angiopoietin 2 receiver operating characteristic curves. Those plot points in the left uppermost region represent more accurate values.

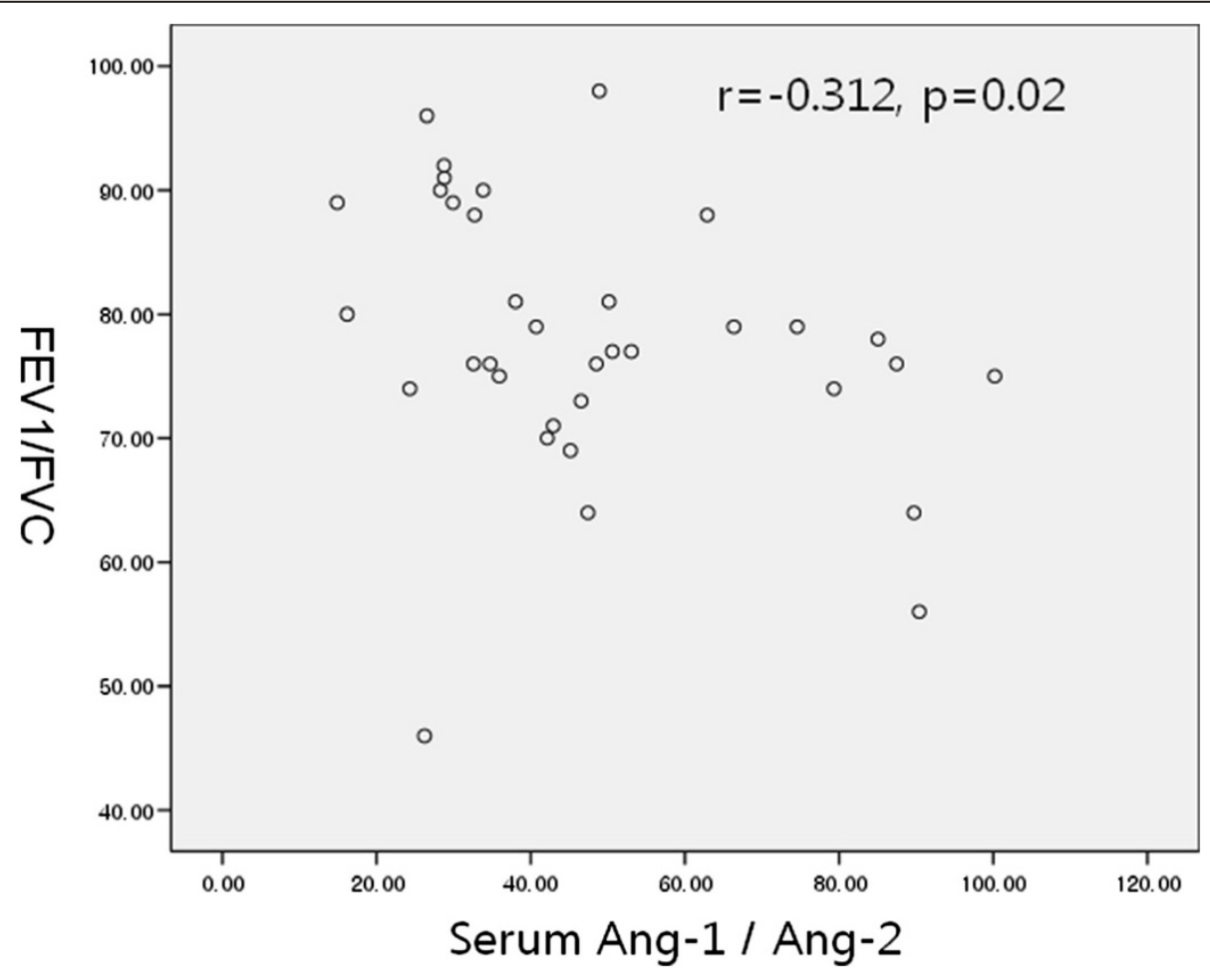

Figure 3 Association of the angiopoietin 1/angiopoietin 2 ratio with FEV1/FVC in patients with asthma. 


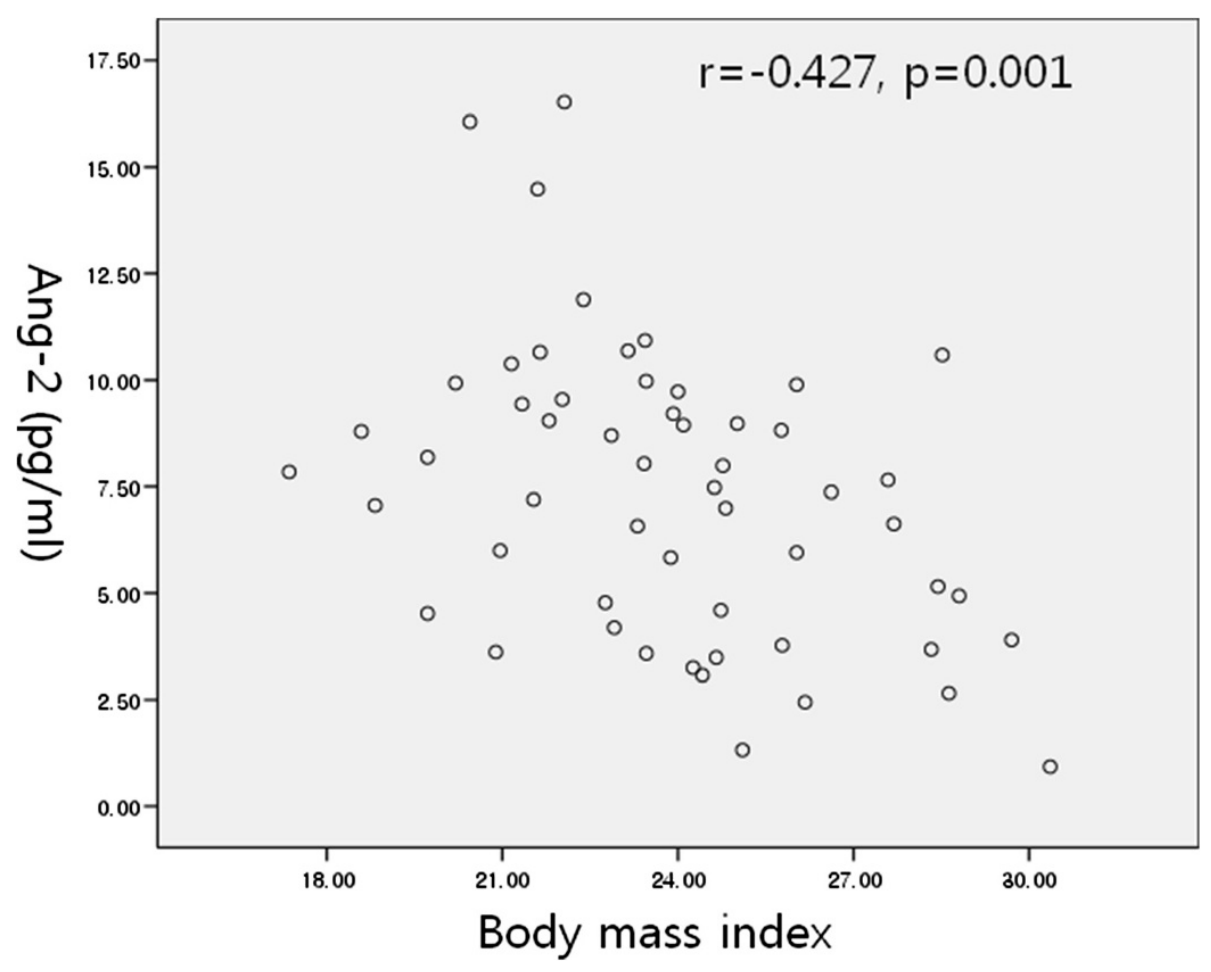

Figure 4 Relationship between angiopoietin 2 and body mass index in patients with asthma.

organization and Ang-1 stabilizes the newly formed vessels [40].

In patients, circulating Ang-2, VEGF, and von Willebrand factor (VWF) levels are increased during ALI/ ARDS or sepsis [11,13,41]. High Ang-2 levels correlate with impaired pulmonary gas exchange [11]. Circulating Ang-2 is associated with pulmonary permeability edema, and the occurrence and severity of ALI/ARDS in patients with and without sepsis [42]. The correlation of Ang-2 with VWF suggests the activated endothelium as a common source [42].

In our patients, the levels of circulating serum Ang-2 did not differ between normal controls and asthmatic patients, whereas the serum Ang-1 levels were increased in asthmatic patients. These results support the hypothesis that high Ang-2 levels, which antagonize the protective role of Ang-1, are involved in the increased pulmonary permeability that leads to asthma $[11,13,41]$. The serum Ang-1/Ang-2 ratio was related to the severity of lung impairment, suggesting a contributory role for Ang-1/Ang-2 in the pathogenesis of bronchial asthma. However, additional studies, including serial serum and alveolar compartment measurements of Ang-1/Ang-2 and blocking studies, are necessary to confirm this hypothesis. The serum Ang-2 levels in our patients with asthma are comparable to those reported in patients with severe asthma by Tseliou et al. [20], who reported higher Ang-1 and Ang-2 levels in patients with severe asthma. This discrepancy may be explained by the patient recruitment and serum sampling protocols used in our study. In animal models, Ang-1 levels were shown to be decreased in asthma and to protect against airway inflammation and hyperreactivity in asthma [43]. In contrast to the study of Simon [43], the serum Ang-1 levels in the present study were increased in patients with asthma compared to the controls, suggesting a difference in angiopoietin-producing cells between humans and other animals.

Interestingly, we found that serum Ang-2 was negatively correlated with BMI, suggesting that obesity reduces the serum levels of Ang-2 produced by endothelial cells and monocytes, resulting in imbalanced angiopoietin function. This study has a number of limitations related to the small number of patients and the retrospective nature of the study. Therefore, additional studies are needed of larger cohorts of asthma patients with different disease severities.

\section{Conclusions}

The serum Ang-1 levels were higher in the asthmatic subjects than in the controls, and the serum Ang-1/ Ang-2 ratio was correlated with lung function, indicating that serum angiopoietins may aid in the diagnosis of asthma.

\section{Competing interests}

The authors declare that they have no competing interests. 


\section{Authors' contributions}

MKY carried out the immunoassays, drafted the manuscript. LPH performed the statistical analysis. PSW and PCS participated in the acquisition of clinica data and in its design of the study. JAS conceived of the study, participated in its design and coordination and helped to draft the manuscript. Al authors read and approved the final manuscript.

\section{Acknowledgments}

This research was supported by Basic Science Research Program through the National Research Foundation of Korea (NRF) funded by the Ministry of Education (2013R1A1A2005465) and Soonchunhyang University Research Fund.

Received: 23 March 2014 Accepted: 18 August 2014

Published: 2 September 2014

\section{References}

1. Corrigan CJ, Wang W, Meng Q, Fang C, Wu H, Reay V, Lv Z, Fan Y, An Y, Wang YH, Liu YJ, Lee TH, Ying S: T-helper cell type 2 (Th2) memory $T$ cell-potentiating cytokine IL-25 has the potential to promote angiogenesis in asthma. Proc Natl Acad Sci U S A 2011, 108:1579-1584.

2. Al-Muhsen S, Johnson JR, Hamid Q: Remodeling in asthma. J Allergy Clin Immunol 2011, 128:451-462.

3. Kristan SS, Malovrh MM, Silar M, Kern I, Flezar M, Kosnik M, Suskovic S, Korosec P: Airway angiogenesis in patients with rhinitis and controlled asthma. Clin Exp Allergy 2009, 39:354-360.

4. Li X, Wilson JW: Increased vascularity of the bronchial mucosa in mild asthma. Am J Respir Crit Care Med 1997, 156:229-233.

5. Hoshino M, Takahashi M, Aoike N: Expression of vascular endothelial growth factor, basic fibroblast growth factor, and angiogenin immunoreactivity in asthmatic airways and its relationship to angiogenesis. J Allergy Clin Immunol 2001, 107:295-301.

6. McDonald DM: Angiogenesis and remodelling of airway vasculature in chronic inflammation. Am J Respir Crit Care Med 2001, 164:39-45.

7. Puxeddu I, Berkman N, Nissim Ben Efraim AH, Davies DE, Ribatti D, Gleich $\mathrm{GJ}$, Levi-Schaffer F: The role of eosinophil major basic protein in angiogenesis. Allergy 2009, 64:368-374

8. Detoraki A, Granata F, Staibano S, Rossi FW, Marone G, Genovese A: Angiogenesis and lymphangiogenesis in bronchial asthma. Allergy 2010, 65:946-958.

9. Burgess JK, Boustany S, Moir LM, Weckmann M, Lau JY, Grafton K, Baraket M, Hansbro PM, Hansbro NG, Foster PS, Black JL, Oliver BG: Reduction of Tumstatin in asthmatic airways contributes to angiogenesis, inflammation, and hyperresponsiveness. Am J Respir Crit Care Med 2010, 181:106-115.

10. Rundhaug JE: Matrix metalloproteinases and angiogenesis. I Cell Mol Med 2005, 9:267-285.

11. Parikh SM, Mammoto T, Schultz A, Yuan HT, Christiani D, Karumanchi SA, Sukhatme VP: Excess circulating angiopoietin-2 may contribute to pulmonary vascular leak in sepsis in humans. PLoS Med 2006, 3:e46.

12. Roviezzo F, Tsigkos S, Kotanidou A, Bucci M, Brancaleone V, Cirino G, Papapetropoulos A: Angiopoietin-2 causes inflammation in vivo by promoting vascular leakage. J Pharmacol Exp Ther 2005, 314:738-744.

13. Mammoto T, Parikh SM, Mammoto A, Gallagher D, Chan B, Mostoslavsky G, Ingber DE, Sukhatme VP: Angiopoietin-1 requires P190RhoGAP to protect against vascular leakage in vivo. J Biol Chem 2007, 282:23910-23918.

14. Thurston G, Rudge JS, loffe E, Zhou H, Ross L, Croll SD, azer N, Holash J, McDonald DM, Yancopoulos GD: Angiopoietin-1 protects the adult vasculature against plasma leakage. Nat Med 2000, 6:460-463.

15. Witzenbichler B, Westermann D, Knueppel S, Schultheiss HP, Tschope C: Protective role of angiopoietin-1 in endotoxic shock. Circulation 2005, 111:97-105

16. Eklund L, Olsen BR: Tie receptors and their angiopoietin ligands are contextdependent regulators of vascular remodelling. Exp Cell Res 2006, 312:630-641.

17. Fiedler U, Scharpfenecker M, Koidl S, Hegen A, Grunow V, Schmidt JM, Kriz W Thurston G, Augustin HG: The Tie-2 ligand angiopoietin-2 is stored in and rapidly released upon stimulation from endothelial cell Weibel-Palade bodies. Blood 2004, 103:4150-4156.
18. Kranidioti H, Orfanos SE, Vaki I, Kotanidou A, Raftogiannis M, Dimopoulou I, Kotsaki A, Savva A, Papapetropoulos A, Armaganidis A, GiamarellosBourboulis EJ: Angiopoietin-2 is increased in septic shock: evidence for the existence of a circulating factor stimulating its release from human monocytes. Immunol Lett 2009, 125:65-71.

19. Wong MP, Chan SY, Fu KH, Leung SY, Cheung N, Yuen ST, Chung LP: The angiopoietins, tie2 and vascular endothelial growth factor are differentially expressed in the transformation of normal lung to nonsmall cell lung carcinomas. Lung Cancer 2000, 29:11-22.

20. Tseliou E, Bakakos P, Kostikas K, Hillas G, Mantzouranis K, Emmanouil P, Simoes D, Alchanatis M, Papiris S, Loukides S: Increased levels of angiopoietins 1 and 2 in sputum supernatant in severe refractory asthma. Allergy 2012, 67:396-402.

21. Makinde TO, Agrawal DK: Increased expression of angiopoietins and Tie2 in the lungs of chronic asthmatic mice. Am J Respir Cell Mol Biol 2011 44:384-393.

22. Kanazawa H, Asai K, Tochino Y, Kyoh S, Kodama T, Hirata K: Increased levels of angiopoietin-2 in induced sputum from smoking asthmatic patients. Clin Exp Allergy 2009, 39:1330-1337.

23. Global Initiative for Asthma (GINA): Global strategy for Asthma Management and Prevention. NHLBI/WHO workshop report. Bethesda, MD: National Institutes of Health, National Heart, Lung, and Blood Institute; 1995. NIH publication no. 95-3659.

24. Park SW, Lee YM, Jang AS, Lee JH, Hwangbo Y, Kim DJ, Park CS: Development of chronic airway obstruction in patients with eosinophilic bronchitis: a prospective follow-up study. Chest 2004, 125:1998-2004.

25. Park CS, Kim YY, Kang SY: Collection between RAST and skin test for inhalant offending allergens. J Korean Soc Allergol 1983, 3:1-9.

26. Adams KF, Schatzkin A, Harris TB, Kipnis V, Mouw T, Ballard-Barbash R, Hollenbeck A, Leitzmann MF: Overweight, obesity, and mortality in a large prospective cohort of persons 50 to 71 years old. N Engl J Med 2006, 355(8):763-778.

27. McGee DL: Body mass index and mortality: a meta-analysis based on personlevel data from twenty-six observational studies. Ann Epidemiol 2005, 15:87-97.

28. Flegal KM, Carroll MD, Ogden CL, Johnson CL: Prevalence and trends in obesity among US adults, 1999-2000. JAMA 2002, 288:1723-1727.

29. Carmeliet P: Angiogenesis in health and disease. Nat Med 2003, 9:653-660.

30. Ferrara N, Gerber HP, LeCouter J: The biology of VEGF and its receptors. Nat Med 2003, 9:669-676.

31. Neufeld G, Cohen T, Gengrinovitch S, Poltorak Z: Vascular endothelial growth factor (VEGF) and its receptors. FASEB J 1999, 13:9-22.

32. McDonald DM: Angiogenesis and remodeling of airway vasculature in chronic inflammation. Am J Respir Crit Care Med 2001, 164(10 Pt 2):S39-S45.

33. Simon MP, Tournaire R, Pouyssegur J: The angiopoietin-2 gene of endothelial cells is up-regulated in hypoxia by a HIF binding site located in its first intron and by the central factors GATA-2 and Ets-1. J Cell Physiol 2008, 217:809-818

34. Thurston G: Role of Angiopoietins and Tie receptor tyrosine kinases in angiogenesis and lymphangiogenesis. Cell Tissue Res 2003, 314:61-68

35. Holash J, Maisonpierre PC, Compton D, Boland P, Alexander CR, Zagzag D, Yancopoulos GD, Wiegand SJ: Vessel cooption, regression, and growth in tumors mediated by angiopoietins and VEGF. Science 1999, 284:1994-1998

36. Salvato G: Quantitative and morphological analysis of the vascular bed in ronchial biopsy specimens from asthmatic and non-asthmatic subjects. Thorax 2001, 56:902-906.

37. Hashimoto M, Tanaka H, Abe S: Quantitative analysis of bronchial wall vascularity in the medium and small airways of patients with asthma and COPD. Chest 2005, 127:965-972.

38. Kumar SD, Emery MJ, Atkins ND, Danta I, Wanner A: Airway mucosal blood flow in bronchial asthma. Am J Respir Crit Care Med 1998, 158:153-156.

39. Paredi P, Kharitonov SA, Barnes PJ: Faster rise of exhaled breath temperature in asthma: a novel marker of airway inflammation? Am $J$ Respir Crit Care Med 2001, 165:181-184.

40. Paredi P, Barnes PJ: The airway vasculature: recent advances and clinical implications. Thorax 2009, 64:444-450.

41. Orfanos SE, Kotanidou A, Glynos C, Athanasiou C, Tsigkos S, Dimopoulou I, Sotiropoulou C: Angiopoietin-2 is increased in severe sepsis: correlation with inflammatory mediators. Crit Care Med 2006, 35:199-206. 
42. van der Heijden M, van Nieuw Amerongen GP, Koolwijk P, van Hinsbergh WWM, Groeneveld ABJ: Angiopoietin-2, permeability oedema, occurrence and severity of ALI/ARDS in septic and non-septic critically ill patients. Thorax 2008, 63:903-909.

43. Simoes DC, Vassilakopoulos T, Toumpanakis D, Petrochilou K, Roussos C, Papapetropoulos A: Angiopoietin-1 protects against airway inflammation and hyperreactivity in asthma. Am J Respir Crit Care Med 2008, 177:1314-1321.

doi:10.1186/1471-2466-14-143

Cite this article as: Moon et al: Serum angiopoietin is associated with

lung function in patients with asthma: a retrospective cohort study.

BMC Pulmonary Medicine 2014 14:143.

\section{Submit your next manuscript to BioMed Central and take full advantage of:}

- Convenient online submission

- Thorough peer review

- No space constraints or color figure charges

- Immediate publication on acceptance

- Inclusion in PubMed, CAS, Scopus and Google Scholar

- Research which is freely available for redistribution 